\title{
Assessment of Dietary Management in AODCI-WDF Diabetes Network in
}

\section{Provinces of Côte d'Ivoire}

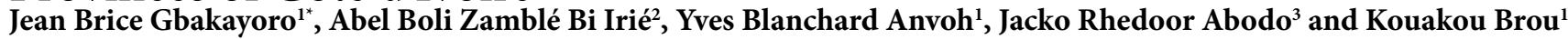

${ }^{1}$ Food Safety and Nutrition Laboratory, Nangui Abrogua University, Abidjan, Côte d'Ivoire

${ }^{2}$ Laboratory of Microbiology and Biotechnology of Food, NanguiAbrogoua University, Abidjan, Côte d'Ivoire

${ }^{3}$ Department of Internal Medicine Endocrinology Diabetology, University FelixHouphouët BoignyAbidjan, Côte d'Ivoire

\begin{abstract}
Introduction: Effective management of diabetes should be holistic, taking into account the roles of different health actors. The objective of this study is to determine the contribution of dietary prescriptions to the balance of blood glucose and metabolic parameters in diabetic patients managed in micro-clinics.
\end{abstract}

Methods: The anthropometric, biological, metabolic parameters of the patients, the follow-up of the dietetic and dietary measures prescribed by the dieticians to the patients were raised. The usual statistics were used to analyze the results.

Results: In total, 17221 patients were managed in the AODCI-WDF micro-clinics, from 2012 to 2017. Only $39 \%$ of patients had benefited from dietary prescriptions (DP), 54\% exclusively of medication prescriptions (MP), 7\% had regular physical activity (PA), and other patients have benefited from the combination of these different treatments (61\% MP+PA, 46\% DP+PA, 93\% MP+DP). Treatments that included dietary prescriptions $(\mathrm{DP}, \mathrm{DP}+\mathrm{PA}, \mathrm{MP}+\mathrm{DP}$ et $\mathrm{MP}+\mathrm{DP}+\mathrm{PA})$ more patients with better control of anthropometric, biological, and metabolic parameters.

Conclusion: The AODCI-WDF diabetes network is a significant contributor to the decentralization of diabetes care through the presence of micro-clinics in many parts of the country. The diets prescribed by dieticians contribute enormously to the control of metabolic parameters of patients.

\section{Introduction}

For more than a quarter of a century, diabetes has become a real global epidemic, affecting all social strata without distinction [1]. Available data show that nearly $80 \%$ of people with diabetes live in low- and middle-income countries, particularly in sub-Saharan Africa [2]. In order to master the expansion of this pathology in Côte d'Ivoire, state authorities set up early specialized structures for the efficient management of the disease. However, these structures are all located in the health region of Abidjan, the administrative capital of Côte d'Ivoire. Therefore, until 2010, the majority of diabetic patients less well of the population, were cared for in these public health centers in Abidjan, namely the CADA (Anti Diabetic Center of Abidjan), the University Hospital of Treichville and the University Hospital of Yopougon [3]. Certainly these reference centers are run by qualified and experienced staff, but that did not prevent from many lost sight especially among resident patients from inside the country. To bring qualified personnel closer to the diabetic populations living inland, a non-governmental organization, the Obesity and Diabetes Association of Côte d'Ivoire (AODCI), in collaboration with Ministry of Health and Public Hygiene (MHPH) and through funding from the World Diabetes Foundation (WDF), initiated the decentralization of diabetes care through the installation of micro-clinics located in regional hospital centers (CHR) of ten (10) regions in Côte d'Ivoire. All of these local structures, covering a large part of the national territory (approximately $3 / 4$ of the country) constitute the AODCI-WDF diabetes network. These micro-clinics are led by a full staff consisting of diabetologists doctors, state-certified nurses, aid-caregivers and dieticians. The objective of this study is to determine the particular contribution of dietary management of diabetic patients in this diabetes network from dietary prescriptions developed by dietitians.

\section{Materials and Methods}

\section{Framework of the study}

This study was conducted in eleven (11) micro-clinics of diabetes, ensuring the outpatient management but also the hospitalization of diabetics in 10 regions of Côte d'Ivoire. These micro-clinics of diabetes are located in a private hospital, a medical center, regional hospital centers and a university hospital center inland the country. These centers welcome some resident patients within the countries who were formerly supported in Abidjan's specialized centers but also other newly diagnosed in those regions.

\section{Type and period of the study}

This is a retrospective descriptive study of the patents supported in these micro-clinics from 2012 to 2017, for a period of 6 years.

\section{Study population}

The study population consisted of all patients in these micro-clinics. Were included in the study, diabetic patients of all ages, both men and women having a support file in the register of diabetics and coming regularly to appointments control.

\section{Variables}

Several anthropometric, biological and metabolic parameters were found in the followed patients. Among the anthropometric parameters weight (in $\mathrm{kg}$ ), height (in $\mathrm{m}$ ), waist circumference (in $\mathrm{cm}$ ), and body mass index helped to classify diabetic patients as lean, normal, or obese. The biological and metabolic parameters concerned blood pressure, glycated hemoglobin, lipid balance (in particular

"Corresponding Author: Dr. Jean Brice Gbakayoro, Laboratory of Nutrition and Food Security, Nangui Abrogoua University, Abidjan, Côte d'Ivoire. 02 BP 801 Abidjan 02, Côte d'Ivoire. Tel: (+ 225) 08376571/43563950; E-mail: gbakayoro.jb2018@hotmail.com

Citation: Gbakayoro JB, Irié ABZ, Anvoh YB, Abodo JR, Brou K, et al. (2018) Assessment of Dietary Management in AODCI-WDF Diabetes Network in Provinces of Côte d'Ivoire. Int J Clin Nutr Diet 4: 137 doi: https://doi. org/10.15344/2456-8171/2018/137

Copyright: ( 2018 Gbakayoro, et al. This is an open-access article distributed under the terms of the Creative Commons Attribution License, which permits unrestricted use, distribution, and reproduction in any medium, provided the original author and source are credited. 
Citation: Gbakayoro JB, Irié ABZ, Anvoh YB, Abodo JR, Brou K, et al. (2018) Assessment of Dietary Management in AODCI-WDF Diabetes Network in Provinces of Côte d'Ivoire. Int J Clin Nutr Diet 4: 138 doi: https://doi.org/10.15344/2456-8171/2018/138

total cholesterol), uric acid. The types of treatment were also identified. The total number of patients in care, those who received the different types of prescription (dietary prescription, medical prescription, regular physical activity), and the combination of these prescriptions (dietary prescription+regular practice of physical activity, prescription medical+regular practice of physical activity, etc.) were determined. The evolution of HbA1C (glycated hemoglobin), blood pressure (BP), total cholesterol (Chol-T), body mass index and uric acid (UA) have been identified.

\section{Data collection and analysis}

The data was collected from the information contained in the patients' files. Data capture and analysis were done using SPSS 18.2 and Excel 2007 software. For the proportion's comparison, Fisher's Corrected Square Chi was used with a significance level of $\mathrm{p}<0.05$.

\section{Results}

\section{Localization of micro-clinics of the diabetes network}

Micro-clinicals are located at Methodist Hospital in Dabou and Anyama CHR for regions of Great-bridges (A),at medical center of Aboudé Mandéké for the region of Agneby Tiassamé (B), at CHR of San-Pédro for the San-Pédro region (C), at CHR of Gagnoa for the Gôh region (D), at CHR of Daloa for the region of Haut Sassandra (E), at $\mathrm{CHR}$ ofYamoussoukro for the Aries region (F), at CHR of Korhogo for the Pororegion $(\mathrm{G})$, at $\mathrm{CHR}$ of Abengourou for the Indénié-
Djjouablin region (H), at CHR of Aboisso for South Comoé region (I), Bouakés university hospital center (CHU) for the Gbêkê region (J) (Figure 1).

\section{Support in the diabetes network AODCI-WDF}

Decentralized care activities in the diabetes network started mostly in 2014 (Table 1) due to some technical difficulties in starting microclinics. The number of diabetics followed, which was approximately 4000 initially in all centers, increased to 17213 in December 2017.

The micro-clinics that host more patients are those of San-Pédro, Yamoussoukro, Daloa, Abengourou with a total number of patients ranging from 2059 to 4051 patients per center, during the study period. The micro-clinics that host an average number of patients are those of Dabou, Aboisso and Bouaké with at least 1000 patients followed. Upon receipt in micro-clinics, several morpho-anthropometric, metabolic and biological controls were required by diabetologist doctornamely the control of BMI, blood pressure (BP), uric acid (AU) level, total cholesterol level (Chol-T) and glycated hemoglobin (HbA1C).

\section{Different types of treatments}

Patients were subjected to several types of treatment (Table 2).These are: $54 \%$ of patients on medication prescriptions (MD), 39\% under dietetic prescriptions (DP), 7\% under regular physical activity (PA), $61 \%$ under $\mathrm{PM}+\mathrm{AP}, 46 \%$ under PD + AP, 93\% under PM + PD.On average, regardless of the type of treatment, $82 \%$ of patients were older than 40 years and $57 \%$ were female.

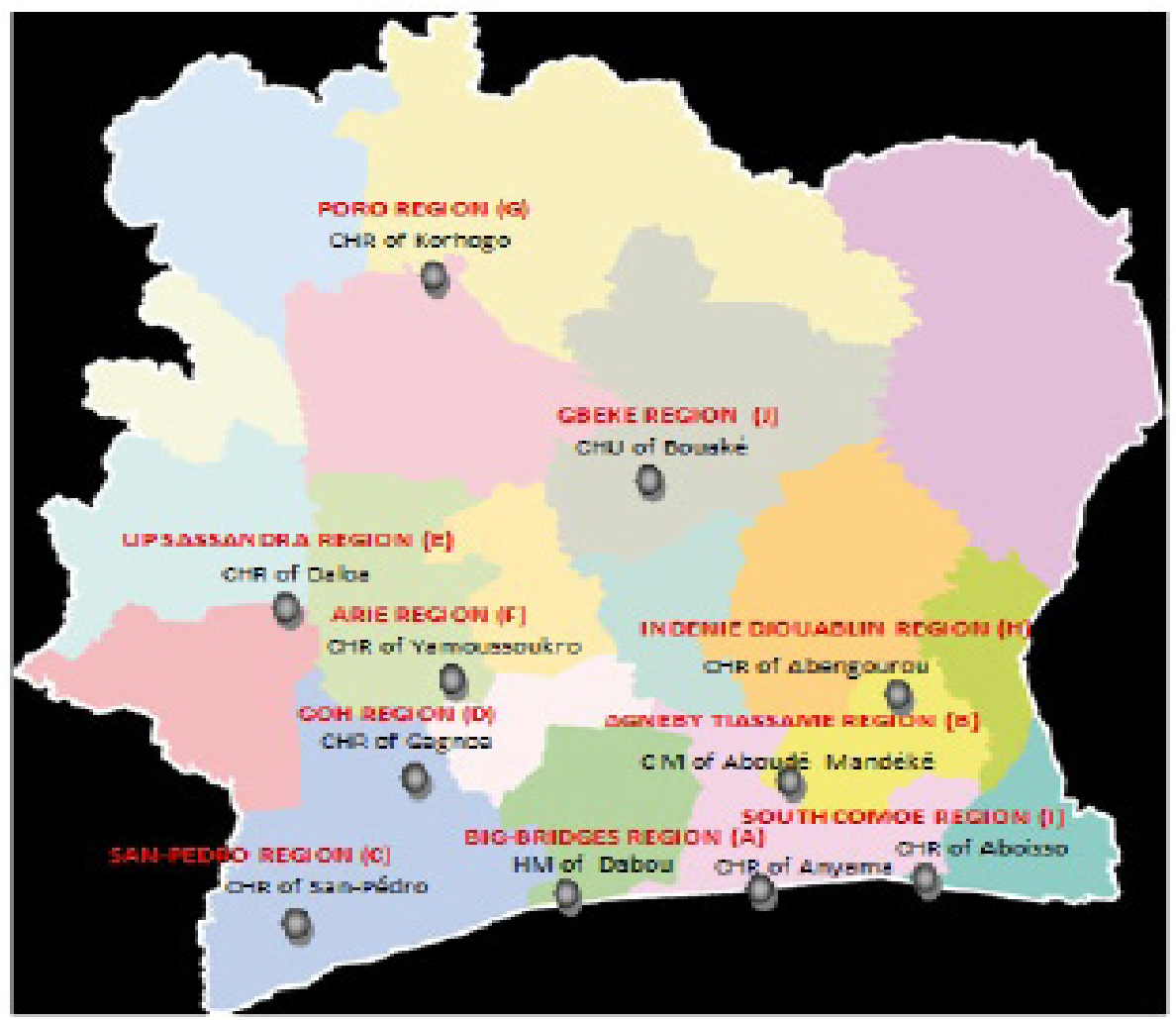

Figure 1: Geographic location of micro-clinics of AODCI-WDF diabetes network in Côte d'Ivoire. HM of Dabou: Methodist hospital of Dabou; C M Aboudé Mandéké: Medical Center of Aboudé Mandéké. CHR: Regional Hospital Center; CHU: University Hospital Center. 
Citation: Gbakayoro JB, Irié ABZ, Anvoh YB, Abodo JR, Brou K, et al. (2018) Assessment of Dietary Management in AODCI-WDF Diabetes Network in Provinces of Côte d'Ivoire. Int J Clin Nutr Diet 4: 138 doi: https://doi.org/10.15344/2456-8171/2018/138

\begin{tabular}{|c|c|c|c|}
\hline Micro-clinic & Effective period of exercise & Total number of diabetics followed & Number of prescribed dietary \\
\hline Dabou & $2014-2017$ & 1026 & 365 \\
\hline Aboudé Mandéké & $2012-2017$ & 503 & 96 \\
\hline San-Pédro & $2013-2017$ & 3024 & 1965 \\
\hline Gagnoa & $2014-2017$ & 452 & 75 \\
\hline Daloa & $2014-2017$ & 2059 & 1209 \\
\hline Yamoussoukro & $2014-2017$ & 4051 & 201 \\
\hline Bouaké & $2014-2017$ & 1105 & 178 \\
\hline Korhogo & $2013-2017$ & 483 & 427 \\
\hline Abengourou & $2013-2017$ & 2976 & 219 \\
\hline Aboisso & $2014-2017$ & 1209 & 89 \\
\hline Anyama & $2015-2017$ & 333 & 6809 \\
\hline Total & - & 17221 & \\
\hline
\end{tabular}

Table 1: Support in diabetes network from 2012 to 2017.

\begin{tabular}{|c|c|c|c|c|c|}
\hline \multirow{2}{*}{ Type of treatment } & Percentage of all diabetics & \multicolumn{2}{|c|}{ Age } & \multicolumn{2}{c|}{ Sex } \\
\cline { 3 - 6 } & & $<40$ years $>$ & 40 years & M & F \\
\hline DP $(n=6809)$ & $39 \%$ & $18 \%$ & $82 \%$ & $40 \%$ & $60 \%$ \\
\hline MP $(n=9207)$ & $54 \%$ & $19 \%$ & $81 \%$ & $45 \%$ & $55 \%$ \\
\hline PA $(n=1205)$ & $7 \%$ & $21 \%$ & $79 \%$ & $42 \%$ & 58 \\
\hline MP+PA ( $\mathrm{n}=10412)$ & $61 \%$ & $20 \%$ & $80 \%$ & $43 \%$ & 57 \\
\hline DP+PA ( $\mathrm{n}=8014)$ & $46 \%$ & $19 \%$ & $81 \%$ & $41 \%$ & 59 \\
\hline MP+DP $(\mathrm{n}=16016)$ & $93 \%$ & $18 \%$ & $82 \%$ & $43 \%$ & $57 \%$ \\
\hline MP+DP+PA ( $\mathrm{n}=17221)$ & $100 \%$ & $18 \%$ & $82 \%$ & $43 \%$ & $57 \%$ \\
\hline
\end{tabular}

Table 2: Different types of patient treatment.

MP: patients under Medication Prescription; DP: patients under diatery Prescription; PA: patients under regular Physical Activity; MP+PA: patients under Medication Prescription and regular Physical Activity; DP+PA: patients under diatery Prescription and regular Physical Activity; MP+DP: patients under Medication Prescription and diatery Prescription; MP+DP+PA: patients under Medication Prescription, diatery Prescription and regular Physical Activity.

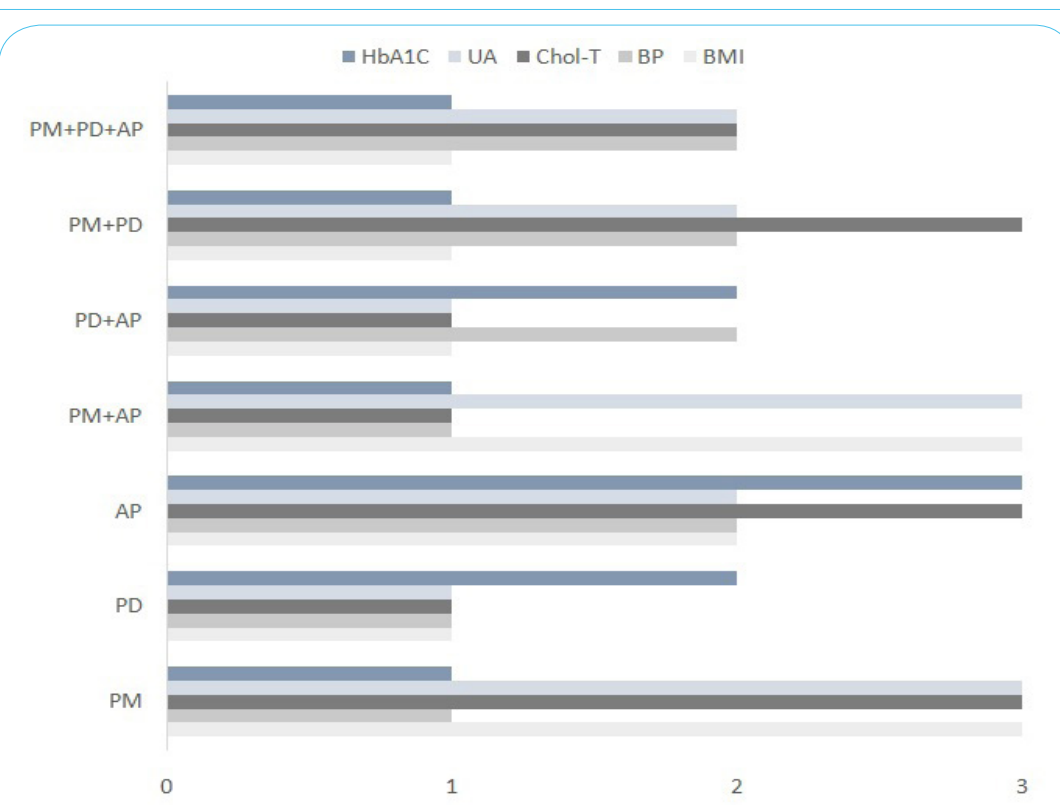

Figure 2: Effects of different types of treatments on the anthropometric, biological and metabolic parameters of patients

UA : Uric acid ; BP : Blood pressure ; BMI : Body mass index ; Chol-T : Total cholesterol ;

HbA1C: Glycated hemoglobin.

1-2: Stable parameter (1: decrease, 2 no significant evolution)

3: unstable parameter (Increase) 


\section{Evolution of metabolic parameters}

For patients under single or combined dietary prescription (DP, $\mathrm{DP}+\mathrm{MP}, \mathrm{DP}+\mathrm{PA}, \mathrm{DP}+\mathrm{MP}+\mathrm{PA}$ ) there is better control of metabolic parameters, with a decrease in some previously high pre-treatment parameters (BMI, HbA1C) and stabilization of others at normal values. However, in patients exclusively under MP or PA or MP+PA there is a regular instability of metabolic parameters, including an increase in AU, Chol-T and BMI (Figure 2).

\section{Discussion}

Aspect we have chosen to take up in this work is the contribution of dietary prescriptions in management of diabetic patients in AODCIWDF diabetes network. This consisted in following the evolution of number of supported patients in these centers, classifying different types of dietetic prescriptions developed by dieticians and determining contribution of dietary prescriptions in the balance of diabetes.

The health network is a collaboration of health professionals in a given geographical area [4]. It is an innovative concept, particularly adapted to the management of chronic diseases, and which is developing much more in Western countries [5]. Following the evolution of number of patients managed in diabetes network is a way of gauging evolution of the prevalence of pathology [6] in these different regions but also makes it possible to assess the impact on the population, recently initiated decentralization. Our results indicate a gradual increase of the number of followed-patients in the microclinics, which went from around 4000 to 17221 in 6 years. This shows that the supply of care now available in these regions is favorably appreciated by the populations. However, to better evaluate the prevalence of diabetes in these regions and in turn in Côte d'Ivoire in general, it would be wise to see a more comprehensive survey after that conducted in 1979 , which estimated at $5.79 \%$ the prevalence of diabetes in the Ivorian's population [7]. This increase in the number of patients monitored in these micro-clinics, corroborates with the forecasts of international organizations for monitoring diabetes pathology (World Diabetes Foundation, International Diabetes Federation, World Health Organization) that predict an increase in the number of diabetics in developing countries [8] to which Côte d'Ivoire belongs.

All existing recommendations indicate that an appropriate diet and regular physical activity are the "keystone" of the therapeutic management of diabetes [9]. However, dietary prescription must be personalized, that is to say, respect patient's eating habits and give a good distribution of macronutrients according to the metabolic balance and the nutritional needs of the patient. Also, physical activity must be adapted to the possibilities of each patient and strictly combined with dietary prescriptions [10]. A good follow-up of these recommendations leads to an improvement in the metabolic status (insulin sensitivity, glycemic level, blood pressure, lipid profile, etc.) and is useful for weight control [11,12]. Despite importance and positive impact of good follow-up of dietary measures and regular practice of physical activity in the balance of the diabetes, our results show that only $39 \%$ of patients of diabetes network AODCI-WDF had received dietary prescription and 7\% reported practicing regular physical activity. This small proportion of patients subject to these dietetic prescriptions duly elaborated by dieticians, could be explained by cost of these dietary prescriptions considered high, estimated at 5000 FCFA and which is independent of overall financial charges of medical treatment and periodic regular checks to which patients are subjected. As a palliative measure, some patients undergo self-medication in dietetics by following non-personalized dietary advice that is arbitrarily recommended by other patients .Moreover, besides the cost, many patients had an optional opinion on the dietary's prescription while they described as essential and indispensable, medical prescriptions given by doctor diabetologist because they considered useful to allow them to maintain a better state of health. The low physical activity observed in our study has also been observed in many other type 2 diabetic patients, such as those in Mali [13] and other countries around the world [14,15].This could be largely explained by lack of knowledge of beneficial effects of physical activity by patients but also by lack of a habit of regular physical activity prior to the onset of the disease.

A good control of metabolic parameters in diabetic patient, makes it possible to delay or prevent occurrence of complications related to the diabetic pathology [16], especially when these have not appeared yet. Besides, a good control of blood glucose can balance HbA1C, that of Chol-T to have a controlled blood pressure and of uric acid (UA), microalbuminuria and proteinuria to avoid the occurrence of renal failure $[17,18,19]$. Our results indicate that the different groups of patients who benefited from dietary prescriptions (DP, DP+PA, $\mathrm{DP}+\mathrm{MP}, \mathrm{DP}+\mathrm{MP}+\mathrm{PA}$ ) had better control of metabolic parameters while those exclusively under MP, PA or MP + PA had less control over some of these parameters. This is because DP helping patients to make better choices in the quantity and quality of foods have been shown to be when they are well followed in the long term, very useful for the balance of metabolic parameters [20]. This kind of positive evolution has also been observed in several other studies [21,22] for patients who regularly adhere to recommendations. Also, the combination of these three prescriptions $(\mathrm{PD}+\mathrm{PM}+\mathrm{AP})$ remains the best of the recommendations for a good management of the pathology $[23,24,25]$.

\section{Conclusion}

AODCI-WDF diabetes network contributes significantly to decentralization of diabetes care in Côte d'Ivoire. The presence of dieticians in the different teams has a positive impact because it allows a better awareness of patients in dietetics but also helps the application of dietary measures (dietary prescription and physical activity).This allows, in addition to drug treatments, to achieve a balance of blood glucose and metabolic parameters.

\section{Contributions of Authors}

Gbakayoro Jean-Brice is the lead author of this work. He did the initial drafting of work. Boli Zamblé Bi Irié Abel and Anvoh Yves Blanchard enriched statistical analysis and contributed to discussion. Abodo Jacko Rhedoor initiated this work in his capacity as president of AODCI (Association Obesity and Diabetes of Côte d'Ivoire), structure that executed installation of micro-clinics therefore, of diabetes network AODCI-WDF. Brou Kouakou supervised this work. All authors participated, read and approved final version of manuscript.

\section{Funding}

We thank World Diabetes Foundation (WDF) for funding installation of micro-clinics of diabetes in 10 regions of Côte d'Ivoire and AODCI for success of execution of this project. We also thank 
Citation: Gbakayoro JB, Irié ABZ, Anvoh YB, Abodo JR, Brou K, et al. (2018) Assessment of Dietary Management in AODCI-WDF Diabetes Network in Provinces of Côte d'Ivoire. Int J Clin Nutr Diet 4: 138 doi: https://doi.org/10.15344/2456-8171/2018/138

all dietitians of micro-clinics of diabetes network AODCI-WDF who contributed greatly to realization of this work by collecting data.

\section{Competing Interests}

The authors declare that they have no competing interests.

\section{References}

1. International Diabetes Federation (2013) Diabetes Atlas 6th edition.

2. Popkin B (2002) The shift in stages of the nutritional transition in the developing world differs from past experiences. Public Health Nutr 5: 205214.

3. Adouéni KV, Ankotché A, Azoh A, Sibailly P, Derbé A, et al. (2012) Diabetic patient management in Côte d'Ivoire on the decentralization mode. Elsevier MassonP88.

4. Hanaire-Broutin H, Chauchard MC, Mozy Le-Cadroy S, Connan L (2002) Care Networks: Multidisciplinarity and team. Example of the Regiona Diabetology Network of Midi-Pyrénnée [DIAMIP]. J Gynecol Obstret Biol reprod 31: 4S39-4S44.

5. Diallo MM, Baldé M, Lokrou A (2013) Access to diabetes care in sub-Saharan Africa: assessment of a diabetes network in Guinea. Medicine of metabolic diseases flight 7: 1-5.

6. Goldberg M, Zins M (2012) Cohort studies: principles and method. A cohort of health care cohorts.

7. Zmirou D (1979) Epidemiology of diabetes in Côte d'Ivoire [thesis] Grenoble: University of Grenoble.

8. International Diabetes Federation (2016) Atlas of diabetes IDF 6th edition. Organization World Health Report, World Report Diabetes.

9. Attali JR, Falcoff H, Andriamanga C, Bouché C, Ertel PV, et al. (2013) Strategy of management of diabetic patients with type 2 excluding decision in charge of complications. National Agency of accred and Health Assessment.

10. Duclos M, Gautier JF (2009) Physical activity and type 2 diabetes. Medicine Metabolic diseases.

11. Sigal RJ, Kenny GP, Wasserman DH (2006) Physical activity/exercise and type 2 diabetes: a consensus statement from the American Diabetes Association. Diabetes Care 29: 1433-1438.

12. Wing RR, Goldstein MG, Acton KJ, Birch LL, Jakicic JM, et al. (2001) Behavioral science research in diabetes: lifestyle changes related to obesity, eating behavior and physical activity. Diabetes Care 24: 117-123.

13. Aïssatou C, Huguette TO, Isabelle G (2009) Belief and eating practices in type 2 diabetics in Bamako (Mali). Nutrition and dietetics notebook 44: 132-142.

14. Badruddin N, Basit A, Hydria MZI, Hakeem R, et al. (2002) Knowledge, Attitude and practices of patients visiting at diabetes care unit. Pak J Nut.1: $99-102$.

15. Canadian Diabetes Association (2003) Clinical practices guidelines for the prevention and management of diabetes in Canada expert commitee. Can J Diabetes $27: 1$ - 163.

16. Grimaldi A (2000) Diabetology, Internship Issues. Recommendations ANAES: monitoring of diabetic patients with type 2 excluding monitoring complications. Pierre and Marie Curie University.

17. Krzesinski JM, Weekers L (2005) Hypertension and Diabetes. Medical Review Liege 60: 572-577.

18. Smelten N, Krzesinski JM (2009) Management of chronic renal failure before dialysis. Rev Med Liège 64: 79-85.

19. Zanchi A, Anne C, Menno (2014) Renal insufficiency and diabetes: the precautions to take. Forum Med Switzerland 14: 100-104.

20. Frida T, Mireille T, Cisse W (2001) Evaluation of glycemic balance from 4 year retrospective study of 427 diabetics followed at Yalgado Ouedraogo National Hospital Center. Doctoral Thesis in Medicine University of Ouagadougou, Training and Research Unit of Health Sciences, Burkina Faso.

21. Lennon D, Nagle F, Stratman F, Shrago E, Dennis S, et al. (1985) Diet and exercise training effects on resting metabolic rate. Int J Obes 9: 39- 47

22. Barnard RJ, Jung T, Inkeles SB (1994) Diet and exercise in the treatment of NIDDM, The need for early emphasis. Diabetes Care 17: 1469- 1472.
23. High authority of health (2013) Medicinal Strategy for Glycemic Control of Type 2 Diabetes. Recommendations for Clinical Practice.

24. Bacle N (2003) Dietary Diabetic type 2, The review of the practitioner General medicine Volume 17 No. 602, 191-200.

25. Eriksson KF, Lindgärde $F$ (1991) Prevention of type 2 (noninsulindependent) diabetes mellitus by diet and physival exercise. Diabetologia 34: 891- 898. 